\title{
CUIDAR PARA UM ENVELHECER SAUDÁVEL: A CONSTRUÇÃO DE UM PROCESSO EDUCATIVO COM MULHERES RURAIS
}

\author{
CARING FOR AHEALTHYAGING: THE CONSTRUCTION OF AN \\ EDUCATIONAL PROCESS WITH RURAL WOMEN \\ PARA UNA VEJEZ SANA: LA CONSTRUCCIÓN DE UN PROCESO \\ EDUCATIVO COM MUJERES DE LAZONARURAL
}

Marilene Rodrigues Portella'

\begin{abstract}
RESUMO: Este estudo identifica uma proposta de prática assistencial, que teve por objetivo a construçāo de um processo educativo, para um envelhecer saudável, com mulheres rurais, a partir de suas práticas culturais de saúde. O Marco Conceitual adotado, foi construido com base no referencial do "cuidado cultural", de Madeleine Leininger e na concepção pedagógica de Paulo Freire. Um processo de cuidar/educar, onde enfermeira e grupo, compartilham seus saberes, através do diálogo reflexivo e buscam "práticas culturais de saúde" que contribuam para um envelhecer saudável.
\end{abstract}

PALAVRAS CHAVE: cuidado cultural, mulher rural, envelhecer saudável

\section{APRESENTANDOATEMÁTICA}

Este estudo é conseqüência da dissertação de mestrado que defendi em 1998, intitulada - CUIDAR PARA UM ENVELHECER SAUDÁVEL: a construção de um processo educativo com mulheres de uma comunidade rural de Passo Fundo/RS. Pretendo mostrar o processo de cuidar/educar da enfermeira, numa comunidade rural, a partir do desenvolvimento de uma prática assistencial de enfermagem junto a um grupo de mulheres com foco centrado num processo educativo para um envelhecer saudável.

Ao observarmos a natureza humana e o ambiente que nos cerca, percebemos que envelhecer é um fenômeno natural, normal e universal. Porém, o processo do envelhecimento humano resulta não só de fatores biológicos, como também de fatores ambientais e sofre influência dos hábitos cultivados durante o curso da vida (Smokvina, 1984. Neri, 1993, 1995, Netto, 1996).

Nossa prática, e as observações do dia-a-dia, tem nos mostrado que ninguém envelhece da mesma maneira ou no mesmo ritmo. Também faz parte do conhecimento comum que na velhice, o idoso se toma mais lento e precisa mais tempo que o jovem para se recuperar, após um periodo de esforço físico ou mental. Sabe-se ainda, que ele é mais susceptivel a doenças, a acidentes pessoais e ao estresse, necessitando portanto, de cuidado.

O homem sempre se valeu do cuidado com o propósito de manter-se com saúde. Neste sentido, Colliére (1986) afirma ser o cuidado parte integral da vida e que nenhum tipo de vida pode sobreviver sem cuidado. Entretanto, $o$ ato de cuidar sempre foi visto como uma particularidade feminina.

A mulher, através dos tempos, sempre exerceu o papel de cuidadora do lar, provendo a alimentação e assumindo o cuidado com os filhos, quando não, da comunidade (as benzedeiras, parteiras..). desta forma, o cuidado, em muitas culturas tornou-se uma exclusividade feminina

'Professora Adjunto I do Curso de Enfermagem do ICB/UPF. Mestre em Enfermagem. Doutoranda do Curso de Doutorado em Enfermagem da UFSC. 
(Bertoncini, 1991, Budo, 1997, Antunes; Oliveira, 1994, Zambonini, 1995, Silva, 1998).

A mulher rural, no seu contexto histórico-cultural, com a responsabilidade de gerar, criar, educar e produzir, constrói sua visão de mundo. Seus hábitos de vida diária refletem sua condição de saúde, doença e de envelhecimento. Ela trabalha lado a lado do marido e filhos na lavoura, exerce também atividades dentro do lar, assume a educação dos filhos, uma tarefa exclusivamente feminina. Mesmo estando grávida, não são poupadas do exaustivo trabalho da lavoura, sendo que muitas delas ganham os filhos quando voltam de uma jornada árdua na lavoura, sem ao menos o auxilio de uma parteira (Antunes; Oliveira, 1994).

Este ser humano, que vive e trabalha na zona rural é submetido a uma sobrecarga de trabalho. Ela cuida da educação dos filhos, da horta, trata os pequenos animais e trabalha na roça. Muitas vezes, é a própria mulher quem garante a sobrevivência da familia com a chamada pequena produção, como; verdura, leite, queijo e came (Scariot, 1995).

Por ter estas características, a mulher do meio rural, necessita de cuidados e práticas culturais de saúde que lhe permita viver e envelhecer de forma saudável.

A enfermeira, ser humano, único, inacabado, em constante processo de aprendizagem, tendo sua própria cultura, desenvolve um trabalho profissional, que tem na sua essência o cuidado (Leininger, 1985), ao interagir com outros seres humanos, entre eles, a mulher idosa rural, ela transmite e compartilha hábitos, num esforço de criar e recriar o processo de viver/envelhecer saudável.

Ainda, profissionalmente, a enfermeira como um ser cuidador, é também um ser educador por excelência. Esta, ao desenvolver o processo de cuidar e portanto, de educar, necessita ter consciência de que os seres humanos com quem interage, no caso as mulheres rurais, são seres em relação com a natureza e com o mundo, que tem uma consciência capaz de captar o mundo e transformá-lo.

Neste contexto, atua em termos de saúde e doença, buscando congruência entre as práticas profissionais de saúde e as práticas populares de saúde desenvolvidas pelas mulheres da zona rural, tomando as práticas de saúde culturalmente satisfatórias e propicias ao envelhecer saudável.

\section{AESCOLHA DO MARCO CONCEITUAL}

Embora o cuidar seja considerado um fenômeno humano universal, assim como o envelhecimento, a maneira como ele se desenvolve é culturalmente condicionada. $O$ cuidar se dá no decorrer do processo de viver/envelhecer de cada um e de maneira diferenciada entre as pessoas. Entretanto, através de gerações e ao longo da história vem sendo influenciado por diferentes contextos; físico, cultural e social (Leininger, 1985).

A escolha de alguns conceitos de Leininger e outros de Paulo Freire, para sustentar o marco conceitual utilizado na prática, deve-se a fato de que ambos em suas idéias tem como princípio o respeito a cultura do ser humano.

Busquei, em Leininger (1985), o cuidado que se ajusta às crenças, valores e modos de vida das pessoas, ou seja, o cuidado considerando a cultura e o contexto social do grupo e por ter sido ela, a primeira enfermeira, a trazer para a prática de enfermagem, o cuidado cultural.

Utilizei-me da concepção pedagógica de Freire, para buscar uma abordagem educativa conscientizadora, contemplando e respeitando os aspectos culturais do envolvidos, visando a busca do envelhecer saudável.

Leininger (1985) defende que a essência da enfermagem é o cuidado, o cuidado transcultural, onde o profissional deve entender os valores, as crenças e hábitos dos individuos com quem interage a fim de preservar, acomodar e/ou repadronizar o cuidado cultural, valendose do saber popular (sistema popular de saúde) e do saber sistematizado (sistema profissional de saúde). 
Freire (1979), em seu principio pedagógico, entende que educação é um compartilhar de saberes, sendo que isto é possivel pelo diálogo, onde todo saber humano tem em si o testemunho do novo saber, a partilha do conhecimento, que só pode acontecer através do diálogo, estabelecendo a partir disso, um processo de ação-reflexão, em cima da realidade, com vistas a transformação.

Assim como, Freire (1979, p.33) coloca, "quando o homem compreende sua realidade, pode levantar hipóteses sobre o desafio dessa realidade e procurar soluçōes", entendo também, que a enfermeira, quando compreende as práticas culturais de saúde das mulheres rurais, pode junto com as mesmas, levantar hipóteses sobre o desafio dessa realidade e juntas procurarem preservar, acomodar e/ou repadronizar suas práticas.

Os conceitos utilizados para esse referencial metodológico (Cultura, Ser Humano/Mulher Rural, Enfermagem/Enfermeira, Saúde e Doença/Envelhecimento e Sociedade/ambiente) foram sendo construidos e identificados, a medida em que consideramos que a interrelação dos mesmos fundamenta a construção de processo educativo, que para este estudo, significa compartilhar saberes.

Nesta proposta, a aprendizagem se dá no contexto do grupo, através da reflexão e do diálogo, sendo possivel reforçar o conhecimento ou alterar a compreensão da realidade. A partir disto, as mulheres rurais, reforçam ou reavaliam suas práticas culturais de saúde para manter ou transformar a realidade e sua relação com o ambiente.

\section{A TRAJETÓRIA METODOLÓGICA}

Para viabilizar este estudo, como técnica de coleta de dados, foi utilizado a observação, a participação e a reflexão, por meio de oficinas, porém não foi utilizado na integra o modelo Observação-Participação-Reflexão (O-P-R) proposto por Leininger. Por ser esta, uma proposta que entende o processo de cuidar também, como um processo de educar, a fase da reflexão não se deteve à metodologia de Leininger e sim, a perspectiva freiriana, da ação educativa, onde, o elemento essencial é o diálogo reflexivo, é a reflexão-ação conjunta, enfermeira e grupo.

Minha atuação nas oficinas, junto ao grupo, baseou-se, então, na perspectiva freiriana de ação educativa modelada na experiência dos "circulos de cultura" ${ }^{2}$, - embora não estivesse utilizando esse itinerário metodológico - desempenhei o papel de facilitador, animador do grupo, respeitando seus saberes e crenças.

"O respeito, então, ao saber popular implica necessariamente o respeito ao contexto cultural. A localidade dos educandos é o ponto de partida para o conhecimento que eles vão criando do mundo. "Seu" mundo, em última análise é a primeira e inevitável face do mundo mesmo... Sua fala, sua forma de contar, de calcular, seus saberes em torno do chamado outro mundo, sua religiosidade, seus saberes em torno da saúde, do corpo, da sexualidade, da morte, da força dos santos, dos conjuros." (Freire, 1993, p.86).

Adotando a reflexão-ação, tendo como papel, animador do grupo, permitiu-me aprender e compartilhar com grupo as práticas culturais de saúde. Também, discutir com as mulheres

\footnotetext{
"Os circulos de cultura" originaram-se nos anos sessenta, quando Paulo Freire se engajava no "Movimento de Cultura Popular" e coordena um projeto denominado "Círculo de Cultura" e "Centros de Cultura". Era uma experiência que reunia de três a vinte pessoas, sem temas a priori. onde o mediador tratava a temática que o grupo propunha, mas acrescentava outros temas para melhor esclarecer o tema geral sugerido pelo grupo popular: O mediador tinha um trabalho de educador comprometido. Sua função era ver que, entre o tema " $A$ " proposto pelo grupo e o tema " $B$ ". haveria um tema "A-B". caberia ao mediador, educador comprometido, viabilizar a compreensão mais crítica da temática proposta pelo povo. Isso era o circulo de cultura.
} 
idosas rurais questões sobre o envelhecimento, a forma de envelhecer e os fatores que interferem à conquista de uma velhice bem sucedida.

Esta prática foi desenvolvida com um grupo de mulheres, de uma comunidade rural, do município de Passo Fundo, localizado na região do Planalto Médio, interior do estado do Rio Grande do Sul. A comunidade era composta de mais ou menos 30 familias, na sua grande maioria, descendentes de italianos, pequenos agricultores, onde a renda familiar era proveniente da lavoura, da horta, da produção do leite e da fabricação de tijolos. O grupo que freqüentava os encontros, variava de oito a dezesseis mulheres, em média, com idade entre 23 e 63 anos, sendo que algumas eram casadas e outras viúvas. Os encontros ocorriam quinzenalmente, com uma hora e meia de duração, num determinado dia da semana conforme determinação das próprias participantes.

\section{AAPLICAÇÃO DO PROCESSO DE ENFERMAGEM}

A minha prática profissional, como enfermeira, somada aos conhecimentos adquiridos e, principalmente, o marco conceitual adotado, levou-me a seguinte definição de processo de enfermagem: - um método de cuidar/educar, na enfermagem, dinâmico, intencional, baseado num marco conceitual e que requer portanto, da enfermeira não só conhecimentos e habilidades específicas, mas também conhecimento das práticas culturais de saúde dos seres humanos com quem interage.

Neste estudo o processo, didaticamente, apresenta-se em quatro etapas:

1. Conhecendo o grupo (levantamento de dados) situação)

2. Identificando e refletindo sobe as práticas culturais de saúde (diagnóstico/

3. Discutindo e construindo com o grupo novas práticas culturais de saúde (intervenção de enfermagem)

4. Analisando o processo de mudança das práticas culturais de saúde (avaliação)

A figura 1, demonstra, mais claramente, as etapas do processo de enfermagem adotado. A aplicação do processo, se deu de forma integral, dinâmica e flexivel, passando por todas as etapas e com possibilidade de, mesmo estando na fase de intervenção de enfermagem, retornar para a fase de levantamento de dados, fazer novo diagnóstico e assim por diante.

\section{AS PRÁTICAS CULTURAIS DE SAÚDE DAS MULHERES RURAIS}

Identificando e refletindo...

Os conceitos utilizados, permitiram referendar que as práticas culturais de saúde ajudam as pessoas a conduzirem suas vidas, a cuidarem de si próprias e avaliarem o que acontece com o corpo, no seu processo de viver/envelhecer. Os depoimentos a seguir demonstram exemplos de práticas culturais de saúde, ou seja, um conjunto de crenças ehábitos a serem transmitidos, aprendidos e compartilhados entre grupo e enfermeira.

Figura 1-Processo de Enfermagem: etapas do processo, conforme o marco conceitual adotado. 
1. Conhecendo o grupo

- Estabelecer dados sobre hábitos, crenças e valores das mulheres rurais;

- identificar práticas culturais de saúde do grupo;

- identificar situações propícias de ensino-aprendizagem junto as mulheres idosas.

O levantamento de dados do grupo, foi feito por meio da observação feita junto ao grupo e na comunidade, através das conversas informais e também da entrevistas feita com base no instrumento guia, com o objetivo de conhecer aspectos da individualidade de cada idosa componente do grupo.

2. Identificando e refletindo sobre as preticas culturais de saúde

- Crenças e valores do grupo em relação as práticas culturais de saúde;

- Práticas culturais de saúde manifestadas pelo grupo;

- Análise e revisão dos dados para identificar temas relevante para o grupo;

- Agrupamento de temas relevantes, que emergiram durante os encontros com o grupo.

Diagnóstico é entendido como a situação encontrada, é uma afirmação sumária, concisa que permite identificar aspectos das práticas culturais de saúde das mulheres rurais, e os torna possiveis de serem preservados, negociados ou repadronizados. De posse dos dados levantados, todo este procedimento diagnóstico foi feito em conjunto com o grupo, visando refletir através do diálogo, as questões problemáticas, encontrar soluções culturalmente congruente e criativas que atendem as necessidades de cada membro do grupo e do grupo como um todo, respeitando seus valores culturais.

3. Discutindo e construindo com o grup£ novas práticas culturais de saúde

- Plano de ações educativa seguindo o princípio freiriano;

- O grupo preserva, acomoda e/ou repadroniza suas práticas culturais de saúde, segundo o referencial cultural de Leininger.

Face ao diagnóstico de enfermagem estabelecido, a enfermeira identificou as práticas culturais de saúde e os temas relevantes para o grupo, no sentido de planejar e implementar as ações educativas de enfermagem.

Para a realização destas ações, o profissional de saúde se colocou como um facilitador, onde a preservação, negociação ou a repadronização das práticas culturais de saúde das mulheres rurais, em suas situações de vida, se deu através do diálogo, exigência existencial do processo educativo formal ou informal.

4. Analisando o processo de mudança das sráticas culturais de saúde.

Realizada com base no comportamento do grupo frente a;

- preservação, negociação e ou repadronização das práticas culturais de saúde;

- aceitação de novas práticas culturais de saúde;

- clareza quanto a importância das ações educativas.

Após instituídas as medidas de intervenção, observou-se que o grupo apresentou sinais de aceitação quanto a preservação e negociação das práticas culturais de saúde. O grupo demonstrou também interesse e reconheceu a importância de repadronizar alguns aspectos de suas práticas. Houve, portanto, resolução do diagnóstico de enfermagem. Esta etapa oportunizou o retorno constante às etapas anteriores, no sentido de construir um processo educativo para um envelhecer saudável, através das ações de enfermagem. ...eu faço umas afumentações que me ensinaram, foi uma antiga benzedeira, 
a dona... é com cachaça, mestrus, caroço de abacate ralado, deixando por sete dias descansar... depois a gente usa para massagear... é um santo remédio... Nossa Senhora! não tem dor que não alivia, é só fazer uma massagem bem feita (Hortência).

Prá dor de cabeça eu faço simpatia, mas quando acontece muito seguido eu até me benzo com uma benzedeira muito boa que tem aqui... a simpatia prá dor de cabeça, funciona mesmo, é só cortar umas rodelas de batatinha, essas de fazer maionese, colocar na testa, deitar num quarto escuro e ficar bem quietinha, por meia hora. Olha! tira a febre da cabeça e a dor passa. Mas quando acontece muito seguido, pode sermau-olhado, inveja, dai é o benzimento que vai ajudar. Eu já fui no médico, por causa da minha dor de cabeça, tomei remédio de tudo quanto é jeito, às vezes melhora, outras vezes fica do mesmo jeito, prá mim a simpatia adianta. (Orquidea).

Se observarmos estas práticas de cuidados apenas com nossos olhos de profissionais, seguramente acharemos que não passam de práticas quaisquer, sem muito sentido. Porém, 0 significado dessas práticas, vem demonstrar que a cultura permeia o processo de viver/envelhecer dos seres humanos, assim como, o entendimento que estes tem, de saúde e doença.

Monticelli (1997, p.122) chama atenção sobre isso dizendo que "através da cultura, os homens comunicam, interagem e muitas vezes perpetuam e desenvolvem seus conhecimentos e suas atividades em relação à vida" ela coloca ainda que a maneira de cuidar, os ritos de cuidados desenvolvidos e como ensinar a cuidar são elementos que não nascem com a mulher. Estes, são aprendidos através de sistemas simbólicos compartilhados no dia-a-dia do processo de viver com outras mulheres.

Cada ser humano é membro de uma cultura e tem necessidade de executar cuidados próprios dessa cultura, precisa relacionar-se, tem direito de ir e vir, é um ser de relaçöes, portanto em constante processo de aprendizagem, em transformação.

\section{Discutindo e construindo...}

Desde o início da implementação do marco na prática assistencial, tive a preocupação de manter as pessoas informadas sobre a dinâmica do trabalho, os objetivos a que me propunha e como dar-se-ia a participação delas no estudo.

A medida que os encontros se somavam e a vivência com as mulheres ocorria, pude aprender e compartilhar saberes, assim como, transmitir conhecimentos, que no meu entender de profissional era necessário.

A sistematização das informações obtidas durante as etapas do processo, serviu de guia para a reflexão sobre as possibilidades e limites das práticas culturais de saúde que deveriam ser preservadas ou mantidas; acomodadas ou negociadas e ainda reorganizadas. Desta forma, através do diálogo reflexivo com as mulheres sobre aquilo que elas compreendiam ou faziam, bem como sobre aquilo que eu, enquanto profissional, compreendia ou fazia, emergia o planejamento conjunto da prática assistencial.

Algumas práticas culturais de saúde desenvolvidas pelas mulheres rurais, consideradas apropriadas, de acordo com o significados atribuidos pela cultura popular e pela cultura profissional, foram identificadas pela ação de preservar. Vejamos no exemplo a seguir:

Eu já sofri muito na minha vida, dos nervos, eu já tive depressão, tive que me tratar, tomar remédio... era por causa das minhas tristezas, eu me atacava muito por causa do problemas... hoje eu me sinto melhor, quando 
quer me atacar, eu saio, vou numa vizinha conversar, tomar mate, dai aquilo me passa. Os filhos já sabem e até dizem... quando a mãe vai tomar mate na vizinha, ou dá as saída dela, é porque a coisa não tá boa... Parece que quando eu converso, quando dou uma saidinha até a vizinha e converso um pouco isso me espairece...(Prímula)

Eu sei como é ruim sentir essas tristezas, eu me angustiava bastante, mas depois que veio a menopausa, lá pelos 47 anos, a coisa ficou pior e eu não sabia... depois de me tratar, é que eu fiquei sabendo que era falta de hormônio...(Cravina)

... quando o espírito não está bem, quando a alma da gente não está bem, o corpo padece. A gente tem que ter uma fé muito grande, tem que achar uma força lá bem dentro da gente, que ajude a gente viver ... tem que procurar uma vontade que venha lá do fundo da alma da gente..(Rosa).

Outras práticas culturais de saúde consideradas menos satisfatórias, no sentido de ajudar na obtenção de resultados mais benéficos para o processo de viver/envelhecer saudável das mulheres rurais, foram identificadas pela ação de acomodar. Como por exemplo, nos depoimentos a seguir:

Aqui na roça, a gente nem se preocupa com a coluna... se é preciso a gente levanta saco de soja, ajuda carregar o caminhão, vai carpir na roça, junta pasto prás vacas. Só vai sentir as costas na hora que deita, é dor disgraçada... é nessa hora que a gente puxa das afumentações, das simpatias...(Primula).

Prá controlar a minha pressão, eu faço o tratamento que o médico mandou, quando ela tá boa eu paro, é que a minha pressão às vezes sobe por causa dos meus nervos, o médico já me disse isso, então quando ela tá boa, eu deixo de tomar os remédios e controlo só com chás caseiros, eu aprendi sobre umas quantas ervas medicinais, prá baixar a pressão, num cursinho que a gente fez esses tempos... (Azaléia)

Por último, aquelas práticas culturais de saúde consideradas pouco saudáveis e que não contribuiam para alcançar resultados de saúde benéficos para as mulheres, foram identificados pela ação de repadronizar. Como por exemplo nas seguintes situações:

olha! esses tempos conversando com as mulher sobre os remédios caseiros, em ensinaram que pra essas tristezas, essas angustia que é muito bom tomar chá de maracujá. Uma vez quando eu me atacei dos nervos, por causa dos problemas lá de casa, fiz um chá bem forte de maracujá, mais gente de Deus! Me deu uma soneira danada, eu fiquei meia boba...(Rosa)

...depois que termina a lida da carneaçăo dos porcos, para lidar com todas aquelas graxeiras, eu fervo bastante água e limpo todas as vasilhas e as mesas, mas depois vou para o tanque lavar os panos de prato na água fria, acho que é isso que me dá a dor nas juntas dos dedos... (Primavera)

Esse planejamento era feito com uma combinação de dois ou mesmo três modos de 
ação ou decisão do cuidado cultural, constituindo-se no verdadeiro processo educativo, ou seja, na construção da aprendizagem, através das trocas de saberes, entre enfermeira e mulheres idosas rurais. Assim, por exemplo, na situação em que Primula fazia suas colocações sobre seus problemas dos nervos e a depressão, foi necessário parar e discutir com o grupo.

Era necessário trazer do conhecimento técnico, o entendimento de depressão, a relação do aparecimento desta no período da menopausa. Era fundamental, averiguar junto a grupo o entendimento que as mesmas tinham sobre o que era depressão, menopausa, doenças dos nervos, as manifestações, as formas de tratar esses problemas, quais as soluções, no seu saber das mulheres idosas, encontradas para minimizar ou eliminar os efeitos desses problemas, quando surgiam e se surgiam para todas. Assim como, quais as soluções apontadas pela enfermeira, a partir do seu saber profissional.

Soluçōes adotadas, como "ir tomar mate na vizinha ...caminhar para espairecer...", essa prática de cuidado de Prímula, decidimos que deveriamos "preservar" ou "manter", constituindo-se num momento de aprendizagem para o grupo e para a enfermeira também. Ao mesmo tempo que se preservava as práticas culturais de saúde de Primula, era necessário "acomodar" as práticas de algumas mulheres do grupo, devido ao entendimento destas, sobre a menopausa, entendo que se dava de forma igual para todas, que usar hormônio viciava as mulheres fazendo elas engordar. Desta maneira discutimos e refletimos sobre as práticas culturais de saúde do grupo. Outras vezes, detectávamos, ainda durante as discussões práticas de cuidados a ser reorganizados e assim o fazíamos. Isto pode ser observado quando por ocasião dos depoimentos sobre as práticas de culturais de saúde que envolviam o uso de chás caseiros. Azaléia demonstrou saber a causa de sua hipertensão, assim como Rosa demonstrou claramente desconhecer e o efeito dos chás medicinais em doses inapropriadas. Também Primavera desconhecia a ação do calor e frio sobre as articulações nos processos inflamatórios.

A identificação da ação de "repadronizar" foi levantada e colocada em prática, através de minha própria explicação teórica, tanto sobre o uso dos fármacos, como sobre o usos de calor e frio nos processos inflamatórios. Era necessário trazer novos conhecimentos ao grupo, através da ação-reflexão, a fim de que, suas práticas fossem repadronizadas.

\section{Analisando as mudanças...}

A utilização do diálogo reflexivo, proposto por Freire, foi fundamental durante a vivência do processo de enfermagem, um verdadeiro processo de cuidar/educar por parte da enfermeira. A busca constante de limites e possibilidades, de maneira conjunta com os co-participantes (mulheres rurais e enfermeira), levam à identificação de semelhanças e diferenças das práticas de cuidados culturais de saúde e também da importância de que se reveste no processo de cuidar, ser também um processo de educar.

A solicitação do grupo, de "querer saber mais" sobre os fatores que pré dispõe o surgimento das dores lombares, sobre o que é "este tal de colesterol", assim como, manifestar desejo de aprender exercícios físicos e adotar estes, para o "alívio da dor das costas", são indícios de aceitação de novas práticas culturais de saúde.

Isto mostra que o cuidar/educar necessita estar culturalmente embasado, de maneira que possa oportunizar ao ser humano a ação-reflexão, transformando a si e ao mundo que o cerca, a fim de, conduzir o seu processo de viver/envelhecer, o mais saudável possivel.

\section{CONSIDERAÇÕES FINAIS}

A contribuição deste estudo, para a enfermagem, tanto para o ensino, como para a prática, reflete-se nas considerações levantadas a partir das reflexōes feitas no decorrer da prática e expostas a seguir: 
A enfermeira deve buscar sempre o seu aperfeiçoamento como ser humano inacabado, inconcluso, em constante processo de aprendizagem. Investirá na sua auto-instrução, assumindose permanentemente como autor e ator da sua história ampliando e desenvolvendo cada vez mais as dimensões do saber, saber fazer e saber ser. Saber este construido através do saber sistematizado e do saber popular.

O processo educativo do ser humano é pessoal, singular! Consiste na história de cada um marcada pela singularidade das suas práticas culturais de saúde, pela sua unicidade, compreendendo o que sabe, o que ignora, o que deseja, quais suas necessidades, valores, crenças e hábitos.

A troca de saberes é um contínuo... é uma necessidade vital! Cada ser humano, pelo encontro com o outro, educa-se, pelos estímulos, desafios e provocaçőes que o sensibiliza, que o convida a compartilhar sua crenças, seus saberes, sua cultura.

Em vários momentos do desenvolvimento do trabalho, percebe-se o emergir dos saberes. Através da aplicação do processo de enfermagem, pode-se evidenciar as necessidades de preservar, acomodar e/ou reorganizar as práticas do grupo e da enfermeira.

É importante salientar a impossibilidade de separar as fases do processo de enfermagem, visto que seus elementos se interligam, interrelacionada e constantemente se completam, sendo um processo dinâmico e contínuo.

A comunicação cuidadores profissionais - grupo, deve atingir a essência, o diálogo reflexivo, onde as trocas de saberes fluem sem imposição de idéias. Possibilitando um processo de cuidar/educar.

$\mathrm{Na}$ esfera das modificações ou transformações das práticas culturais de saúde, como acomodação e repadronização, podem ocorrer com cada membro do grupo, ao próprio grupo e a enfermeira. É o próprio processo educativo.

De uma maneira geral, este estudo possibilitou um processo de cuidar/educar valorizando as referências culturais trazidas pelos "clientes", fato esse que se faz muito importante para a enfermagem, que tradicionalmente está habituada a prestar a assistência vinculada ao modelo biomédico, no qual as pessoas são tratadas de maneira uniforme, a partir de suas doenças, sem considerar suas diferenças.

Outro aspecto bastante importante deste processo é o de que, ao planejar com as mulheres idosas rurais, as práticas culturais de saúde, a enfermeira também teve a oportunidade de rever seus conceitos e valores às vezes tão arraigados na sua cultura profissional. Este processo de cuidar/educar significa muito mais do que passar os conhecimentos técnicos-científicos, implica, também conhecer o significado, os valores, crenças e hábitos que norteiam as vidas dos seres humanos com quem interagem.

ABSTRACT: This study analyses a proposal of nursing assistance. The project proposed has as its goal the construction of an educational process aiming a healthy aging among rural women. It is important to emphasize that these women's cultural health practices were taken into consideration in this research. The conceptual milestones adopted were drawn from Madeleine Leninger's concept of "cultural care" and Paulo Freire's pedagogical ideas. The educational process being proposed is based on the idea of caring/educating in which the nursing professional and the group share experiences through reflective dialog, and seek culural health practices that can contribute on a healthy aging.

KEY WORDS: culture care, rural women, healthy aging

RESUMEN: Este estudio identifica una propuesta de práctica asistencial que tiene como objetivo la construcción de un proceso educativo, para que las mujeres de comunidades rurales alcancen a 
tener una vejez saludable, a partir de sus prácticas culturales de salud. El Marco Conceptual se basa en el "cuidado cultural" de Madeleine Leininger y en la concepción pedagógica de Paulo Freire. Un proceso de cuidar/educar en el que enfermera y grupo comparten lo que saben mediante la reflexión y buscan unas "prácticas culturales de salud" que contribuyan para un envejecimiento saludable.

PALABRAS CLAVE: cuidado cultural, mujer de la zona rural, vejez sana.

\section{REFERÊNCIAS BIBLIOGRÁFICAS}

ANTUNES, H. S.; OLIVEIRA. V. F. A mulher italiana na comunidade de Silveira Martins: uma abordagem de gênero. Cadernos de Pesquisa, Santa Maria, n. 64, p. 01-29, dez. 1994.

BERTONCINI, Fabiana. Mulher na evoluçāo da humanidade. Revista pastoral da Juventude Rural do Brasil. Brasilia, p. 5-23, 1991.

BUDÓ . M. L. D. A mulher como cuidadora no contexto de uma comunidade rural de imigraçăo italiana. Rev. Texto Contexto Enfermagem. Florianópolis, v.6, n.1, p.181-197, jan/abr. 1997.

COLLIERE, Marie Françoise. Inviseble care invisible woman as health care-providers. Internacional Journal of Nursing Studies, Great Britain, v.23, n.2, p.95-112, 1986

FREIRE, Paulo. Conscientização: teoria e prática da libertação: uma introdução ao pensamento de Paulo Freire. Traduçāo por Kàtia de Mello e Silva. São Paulo: Cortez \& Moraes, 1979.

Pedagogia da Esperança: um reencontro com a pedagogia do oprimido. 2. ed. Rio de Janeiro: Paz e Terra, 1993

LEININGER, Madeleine. Teoria do cuidado transcultural. Diversidade e universalidade. In: SIMPÓSIO BRASILEIRO DE TEORIAS DE ENFERMAGEM, 1., 1985, Florianópolis. Anais... Florianópolis: UFSC, 1985. p. 232-254.

MONTICELLI, Marisa. Nascimento como rito de passagem: abordagem para o cuidado às mulheres e recém-nascido. Sảo Paulo: Robel Editorial, 1997.

NERI, Anita Liberalesso (Org): Qualidade de vida e idade madura. Campinas, São Paulo: Papirus, 1993.

Psicologia do envelhecimento. Campinas, São Paulo: Papirus, 1995.

NETTO, Mateus Papaléo. Envelhecimento: desafios na transição do século. In: NETTO, Matheus Papaléo. Gerontologia. São Paulo: Editora Atheneu, 1996. p. 73-76.

SCARIOT, Mariza. Principais caracteristicas das relações de gênero no Capitalismo e Socialismo. In: A mulher trabalhadora rural. Rev. Pastoral da Juventude Rural do Brasil, Brasilia, p. 38-46, 1995

SILVA, Ivone Pereira da. As relaçōes de poder no cotidiano de mulheres cuidadoras. In: KARSCH. Ursula Margarida S.(Org.) Envelhecimento com dependência: revelando cuidadores. São Paulo. EDUC, p. $147-170$

SMOKVINA, Glória J. Envelhecimento: da meia-idade à senescência, In: BEYER, Marjorie; DUDAS, Susan. Enfermagem Médico-Cirúrgica - tratado de prática Clínica. 2. ed. Rio de Janeiro: Guanabara, 1990. v. 1 , cap. 6 , p. $52-67$.

ZAMBONINI, Vaniamar. A mulher trabalhadora rural. Revista pastoral da Juventude Rural do Brasil, Brasilia, p. 24-33, 1995 